\title{
Ensuring Active Participation in School Projects: A Reflection Case Study in the Framework of Education for the Sustainable Development
}

\author{
Maria Kalathaki \\ Ph.D., Med, School Advisor for Science Teachers in Secondary Education, \\ Regional Educational Directorates of Crete, Knossos Avenue 6, Postal Code 71306, \\ Heraklion, Crete, Greece
}

Received: January 5, 2017 Accepted: March 14, 2017 Published: March 16, 2017

doi: 10.5296/jsss.v4i2.10938 URL: http://dx.doi.org/10.5296/jsss.v4i2.10938

\begin{abstract}
Environmental Education with joint efforts by the government, environmental agencies, entrepreneurial initiatives, local authorities and schools play a major role in in promoting students' understanding of environmental concepts, enhancing their awareness on major environmental issues and positive attitude towards natural environment, and cultivating the future active, environmental literate citizen. This research is a case study with synthesis of many interesting approaches, actions and constructive elements of a school project on Environmental Education which designed and applied to meet the principles and methodology of Education for the Sustainable Development. The research method allowed the reflection and assessment of the design, the detailed description of the educational activities, the objectives initially set, the way they were achieved and their impact to those involved, particularly to students and teachers. The study aimed to contribute in the understanding of the framework, procedures, characteristics of the target group and the learning environments, in an open "reading" frame. It also aimed to attribute meaning to the real experience of the participants.

Students' participation in the educational project was very active because of the interesting subject of the project, the link of the study with the management of ecosystems and also the relations that were built up among the participants during the project implementation. The Project utilized the didactic research with the use of various educational techniques which stirred the interest of students and pushed them to get more involved in the educational process, looking more to discover new knowledge. The project focused on learning about the bio-communities and the ways of management and protection to ensure future ecological sustainability and social quality of life. Students visited agro-tourism units in Macedonia and
\end{abstract}


Crete in different ecological environments. Discussions, interviews, round table debates, brainstorming, role play, environmental pathways, guided tours were greatly conducted together with the ICTs in various learning environments inside and outside the school, in the classroom, the libraries, the science laboratory, in the field and in society, kept the students highly interested all over the project implementation.

Keywords: School Environmental Projects, Education for the Sustainable Development, Active citizens, Environmental Education

\section{Introduction}

The preamble of the Earth Charter (2000) is referred to the need of joined effort of the people to bring forth to a sustainable global society, founded on respect for nature, universal human rights, economic justice, and a culture of peace, being one human family and one Earth community with a common destiny in the midst of a magnificent diversity of cultures and life forms. Education needs reorientation in order to build a better future for all, accelerating action for Sustainable Development (SD), setting the agenda for the Education for the Sustainable Development (ESD) beyond 2014, as concluded in the workshops of the World Conference of UNESCO in Nagoya, Japan (UN, 2015). By empowering Lifelong learning, all general education, vocational education and training, non-formal learning and informal learning throughout life results will occur in the improvement of knowledge, skills and competences, participation in societies within a personal, civic, cultural, social and employment-related perspective, including the provision of counseling and guidance services (Erasmus + , 2016). Rio+20 (2012) stressed the importance of the active participation of young people in decision making processes as the current environmental issues have a deep impact on present and future generations, and as the contribution of young people is vital to the achievement of SD. It is recognized from all the needs of intergenerational dialogue and solidarity by recognizing all different views.

The development of Sociology of Education is particularly encouraging the sociological approach to educational problems. It is apparent now, that human actions are a consequence of the different perspectives that people see for the world and axioms that they have about it, dimensions that should be sought and understood in the educational processes and researches. Each course should not be determined by previous perceptions of reality but should be built over time, in ways that are influenced by circumstances. Hence social processes should be considered qualitatively, clearly and thoroughly by formatting data and creating the conditions to interpret the meaning and purpose of the function of human actions (Hargreaves, 1990). There is evidence within the sociology of scientific knowledge that has explored the importance of social negotiation in the production of facts. (Cunningham et al. (2001) and Komis (2004) posited that both true and false beliefs should require sociological explanation. Central to the justification of this approach is the stance that empirical evidence alone underdetermines scientific knowledge, so that, effective learning environments are products of interactions between the specific characteristics of the educational organization and the existing opportunities of experiences providing by the objective entourage. Social construction of knowledge is necessary to move empirical data to established fact (Birch \& Gussow as cited in Vygotsky, 1997).

In terms of students' active involvement in the learning process, the modern didactic literature 
describes directly or indirectly classrooms where students ask, explain, comment, communicate, exchange views and information, support and control the accuracy of the data, juxtapose and retort dialectically in the grounds of different positions, hypothesize, investigate, experiment and finally lead to substantiated opinions, solutions and proposals (Matsagouras, 2007). Therefore, active and collaborative learning processes should help students to understand, not memorize, to promote change in their ideas and to bridge the gap between the activities taking place in school and those that are of cultural original. The cultivation of active and environmentally literate citizens is achieved by developing their knowledge, skills and values and involving them in eco-management and social, political actions and interventions and the most appropriate educational methodology was the application of the discovery teaching method (Kalathaki, 2016). NAAEE (1996) states that Science teaching should be extended beyond the school since children learn from their parents, siblings, other relatives, peers, adults. They learn from the film, television, radio, records and trade books. They also learn from online magazines, from visits to museums and zoos, sporting events, concerts, as well as textbooks and the school environment in general. Teachers should take advantage the wealth of behavioral elements of the broader social context and should exploit the parents and other relevant adult stakeholders in several ways. It is also important for teachers to recognize that much of what the students are learning informally are incorrect, incomplete, poorly understood, or misunderstood, and that basic education can help students to reconstruct this knowledge and to acquire new ones.

Key competences for lifelong learning, in the shape of knowledge, skills and attitudes appropriate to every context, are fundamental for the individuals in a knowledge-based society. The transversal nature of key competences makes them essential and provides added value for the labor market, social cohesion and active citizenship by offering flexibility and adaptability, satisfaction and motivation (EC, 2006). These competencies of communication in any language, in mathematics, science and technology, in learning to learn, social and civic competences, sense of initiative and entrepreneurship, cultural awareness and expression ought to be cultivated in any educational project with emphasis on critical thinking, creativity, initiative, problem solving, risk assessment, decision taking and constructive management of feelings.

Increased satisfaction of students who participate in educational projects is the result of experiences which lead to the achievement of a project's predetermined goals and outcomes. The factors that influence students' satisfaction are many. They are intertwined with each other, and consequently difficult to be clarified and determined. Some of them are the presenters, the social content and the learning related conditions (Wang \& Carlson, 2011). That satisfaction plays role in strengthening the dimensions of environmental citizenship and should be a key outcome for engaging young people. A positive learning environment where one arouses learner's positive emotions, such as fun and interesting outdoor activities, may be part of a fundamental cornerstone to building the socio-cultural context. In preparing young Europeans to be future active citizens, there is a need to foster a culture of democracy in schools by involving students, parents and teachers and by establishing life-long learning processes that will be practiced at the level of the companies' framework. Democracy in schools can also have pragmatic justifications as effective way for creating climate of 
confidence and responsibility (EC, 2007).

Since learning takes place as individuals take different roles in their lives, ESD must be seen as a process that extends throughout our lives. It is very important for young people to actively participate as citizens and to collaborate with at local and international levels in order to solve environmental problems (Karountzou, 2007). Each school's educational and training project should be designed on the basis of the principles of interdisciplinary, lifelong learning and active participation. Promoting active citizenship through the ESD Projects (ESDP), which include the active, creative, critical and global citizen, means to cultivate the future citizen with democratic accountability and individual responsibility who is capable in combining theoretical knowledge with innovative ideas and practices, to develop initiatives, to manage risks and to overcome obstacles (Hernandez \& Monroe, 2000; Huckle, 2006).

Environmental Education (EE) in Greek Secondary Education is voluntary implemented mainly through school projects, beyond the curriculum, and at Environmental Education Centers (EEC) with institutional official framework defined by lows and Ministerial Decisions coming to school through Circulars of the Greek Ministry of Education [laws 1892/1990 (official journal of the Hellenic republic 101tA') and 2986/2002 (official journal of the Hellenic republic 24tA'/13-2-02)], Ministerial Decisions G2/4867/28-8-1992 and G2/4915/16-9-96] and Circulars (e.g. 98498/G7/17-9-04). The School Projects of Environmental Education (SPEE) focuses on the study of environmental issues, mostly of local range and interdisciplinary approach by the environmental teams (Chrisafidis, 2006; Zygouri, 2006). More specifically, the "Open Environmental Classes" Callisto (2008) was a Program guided by the Greek Ministry of Education with an organized three to five-day visit of Secondary students accompanied by their teachers to regions of Greece with special ecological interest (Circular of the Greek Ministry of Education 587/28-11-2008). The Program mainly, targeted the following: a. to update, to make aware and to mobilize students on issues related to the forests, wetlands, biodiversity, sustainability and quality of life; $b$. to develop an anti-consumer model by highlighting the traditional way of life and c. to involve them in the care-management of natural ecosystems. The SPPE "Forest, Biodiversity and Quality of Life" implemented in Meleses Lyceum of Crete, Greece, in 2008, was funded by the above referred Program 'Open Classes Callisto'. The targeting and methodological implementation of the project based on the Strategy for ESD, as it formulated in Vilnius in 2005 (UNECE, 2005).

This research is a case study, with detection and synthesis, of many interesting approaches, actions and constructive elements of the SPPE "Forest, Biodiversity and Quality of Life" with the purpose to understand the internal culture of the educational methodology which enhanced the active participative implementation.

\section{Method}

The project "Forest, Biodiversity and Quality of Life" had been well evaluated and approved by the Greek Ministry of Education within the Environmental Program of 'Open Classes Callisto'. It was implemented in two different environments of Crete and Macedonia. The research attempted to highlight and clarify those factors that allowed and promoted the active participation of the students from the perspective of providing opportunities in the beginning and along the way of the project implementation. 


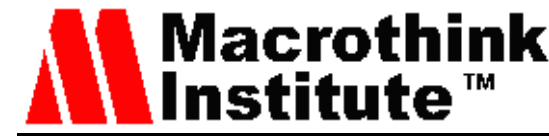

The research is a case study with content analysis, detection and synthesis of many interesting didactic and pedagogic approaches, actions and constructive elements of the studied Project (Cohen \& Manion, 1994; Bell, 1997). The research focused on the specific items and factors that composed the Project's implementation, the applied educational initiatives, designs, methodologies, actions and ideas, the expressed aspects by the students and teachers and external collaborators (Dimitropoulos, 1996). The retrieved data from the archival material of the Project was combined with aspects that expressed in the interviews of three teachers who had the responsibility of design and implementation of the project in the frame of the literature for EE, ESD for the school educational projects, serving the needs of triangulation of research.

The contents of archival material, in printed and digital form, examined in a semi-structured manner, making discourse analysis based on the phrase and paragraph which were defined as recording unit (Iosiphidis \& Spyridakis, 2006; Iosifidis, 2003). The analysis was carried out, based on the meaning and importance attributed from the point of view of the researcher to the content of the archival material (texts, photos, and videos) and interviews. The interviews were conducted in the form of dialogue with documentation. In the critical reading of documents, data mostly retrieved from the Application Form (AF) and the Final Report (FR) of the Project, The unit of the content analysis consisted of the phrase, the paragraph of the text material and the impression given by the "picture" of the multimedia. The research categories were located based on the progress of the analysis of data, depending on the subjects negotiated in the particular thematic areas of the project. The research method of the case study allowed the detection, evaluation and assessment of the design, the detailed description of the educational activities, the objectives initially set, and the way they were achieved, the sense left to those involved (Cohen \& Manion, 1994; Bell, 1997). This study aimed to contribute in the understanding of the framework, the procedures, the target group, the learning environment, in an open "reading" frame. It also aimed to attribute meaning to the reality that actors experienced.

Finally, 7 categories were determined, as following: 1. the topic and themes selection, 2. links to the school curriculum and syllabus, 3. pedagogical objectives and principles of the project, 4. students' involvement in all phases of the project, 5. strengthening communication and relationships, 6. innovative project methodology \& meaningful educational activities and 7. dissemination of the project outputs and outcomes.

\section{Results and Discussion}

\subsection{The Topic and Theme Selection}

In SPEEs, the topic selection is hypothesis of the environmental team. It is agreed upon by the students and teachers. Then it is analyzed based on local, national and global environmental issues. Therefore, collaboration in the choice of subject and objectives makes the students interlocutors and accomplices in the educational process. According to Huckle (2006) there are three ways to start a research topic in an ESD class. First, the students decide the topic by themselves by choosing from a number of selected issues or it is chosen by the teacher. The project subject must stimulate the curiosity and must induce wonder and admiration, as there is no authentic research or significant learning if there is no research that seeks an answer, a solution and an explanation or a decision (Athanasiou, 2008). 


\section{\Institute ${ }_{\text {Math }}^{\text {Macrothink }}$}

The topic should match the interests of students, to be topical, giving investigation and discovery capabilities either in person, or virtually, to be attractive and inspiring for didactic research. It seems that fires of 2007 prompted the environmental team to choose the topic related to the forests (FR). "The choice of theme was shared with students and related to issues of the nearby environment and topical ... After the fires of 2007 and since that year (2008) is a year of "Forest - Green Planet" UNESCO ESD Decade, the students from the beginning of the school year were interested in composing workgroups and preparing an environmental project" (UNESCO, 2005).

\subsection{Links to the School Curriculum and Syllabus}

The links of the Project with the courses taught in Lyceum kept up the interest of students and teachers throughout the school year. In those modules for school-related subject, the teachers of the Project made reports and discussions with all the students of the classes involved, not just those of the environmental team. "In this way we're becoming the dissemination of ideas and results of the Project and the Project was considered to be case of the whole school" (Teacher 1). A large portion of the Project's themes was linked to the curricula of Biology, Environmental Science, History, Economy-Organization and Management, Geography etc. of Secondary Education and this exploited in teaching the courses also in the Project development.

In Biology, the field work in the forests based on the indicated worksheet of the environmental project of the Greek Pedagogical Institute 'Forests-Development-Environment' (PI, 2007). It suggests students to record the species of flora of the forest (number of forest trees, age of trees, tree condition, deforestation etc.), vegetation, animals living in the forest, the abiotic components of soil, temperature and humidity of the forest, to describe human interventions in the forest, the forest protection infrastructure, deforestation, waste bins, dropping litter etc.; to indicate the role of forests, to evaluate its usefulness and to record the thickness of tree trunks, their height estimated, their species and especially their age. On the banks of Lake Kastoria, students recorded the tree species encountered, focused their attention on the different types of leaves and the variety of lake birds, spotted identified bio-information proving traces and developed discussion of the respective plant and zoo communities of Crete which they had previously studied, as stated in the Workbook. "In the forest of Epanosifi Monastry, students learned to measure and calculate easily and quickly the tree height with a simple method based on analogies to similar triangles. During their work in the field, they used a compass and exercised in reading topographic map in the forest area of Mount Vitsi" (FR). "They will observe birds with telescopes when they visit the Prespa Information Centre and the bird watching point in Krina Hill" (AF).

Regarding to history, "The students were able to see and learn about many monuments from prehistory to modern history. "The introduction to primitive life in Dispilio in the Mesolithic era and the Minoan civilization in the students' region, extended their knowledge in the past, connecting their roots with those of the rest Greek" (FR).

As for the course of Informatics, "students had the opportunity to make practice the ICTS theory by using the Internet navigation for inquires and multimedia tools for presentations, negotiating with the as collected data and material, on the tasks assigned to them" (FR). 


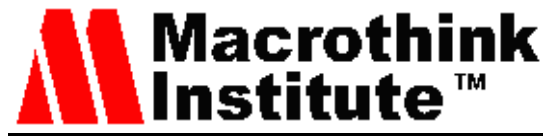

Agro tourism is a mild form of sustainable tourist development and multi-activity in rural areas, which aims to help visitors to learn in depth the rural areas, farming activities, local products, traditional cuisine and daily lives of residents, cultural elements and original features of the region. It also intends to mobilize the productive, cultural and developmental forces of the land, thus contributing to sustainable environmental, economic and social development of rural areas (Agrotouristiki, 2007). "Hostels, traditional food, accommodations that students visited in Houdetsi and San Germanos, the brown bear and wolf protection programs of Arcturus introduced them in interesting management proposals of natural environment and traditional settlements when entered in the microscopes of small researchers, future maybe entrepreneurs, enriching their knowledge of Economics and Business Administration taught in school courses" (Teacher 2). These issues are taught in the course of Economy and Management in Lyceum.

\subsection{Pedagogical Principles and Objectives of the Project}

Objectives of SD referred in many documents of UNESCO and European Union in the same direction of Earth Charter (2000) which ends with the title 'The Way Forward' concluded that the life often involves tensions between important values, making more difficult to make the choices. However, the government, institutions, organizations and other agencies must find ways to harmonize diversity with unity, the exercise of freedom with the common good and short-term objectives with long-term goals. In this way, every individual, family, organization and community will play a vital role under the creative leadership of arts, sciences, religions, educational institutions, media, businesses, nongovernmental organizations, and governments. "Students took their own initiative to make contact with individuals and groups to look for the features and benefits of agro-touristic development and management of natural ecosystems in Crete in comparing with the Prespa and Kastoria (Teacher 1).

Acquiring basic skills (literacy in reading, mathematics, science, language, ICT, civic and learning to learn) is an essential prerequisite in working in a knowledge-based society and educational goals of schools (E-COM, 2007). Regarding the implementation of SPEEs, some of the basic principles desirable to govern the environmental actions are related to the fulfillment of the principle of sustainability, participation in / for the community with action drawing on principles of socio-constructivism and socio-cultural approaches. The project was designed with the principles of multidisciplinary and interdisciplinary approach to systemic approach of environmental issues, the adoption of the principles of collaborative and guided inquiry by using ICT and moreover, the cultivation of values, skills and meta-skills (Aegean, 2004; NTUA, 2007). Designing ESD toward 2013, it's time remembered for the awakening of a new reverence for life, the firm resolve to achieve sustainability, the quickening of the struggle for justice and peace, and the joyful celebration of life (UN, 2015).

The objectives of project were cognitive, scientific, social, aesthetic, and self-educative attitudes, as written in the aims of the AF and as concluded from the describing of the activities in the FR. The activities included an examination of the level of ecological foundation and consciousness, based on Action Level that is, participation in decision making, finding alternatives, participation in political activities, in eco-management actions, and on the life skills such are communication, data analysis etc. (Zahariou, 2007). According to the findings, actions in the classroom or the laboratory were classified within the three general 
approaches of implicit, historical, and explicit approaches, which expressed by Lederman (2004). More specifically, the Project targeted to update, to make aware and to mobilize students on issues related to the forests, wetlands, biodiversity, sustainability and quality of life. The project also aimed to develop an anti-consumer model by highlighting the traditional way of life and to involve them in the care-management of natural ecosystems. In the cognitive goals of AF and FR included "The students get to know the forest bio-synthesis, to develop recording observation skills and sort of life in the forests, data collection and recording, correlations, speculation, etc.... The team investigates and identifies human interventions, such as roads, settlements, logging operations, tourism facilities, etc. and realizes the interaction and interdependence of the natural environment to the economy and development".

\subsection{Students'Involvement in All Phases of the Project}

According to Vosniadou (2001), learning in school requires, among others, set goals and take responsibility for students' own learning. The cognitive activities are not possible without the active participation and involvement. "Teachers helped students to actively participate in all phases project and set objectives to understand new things and built upon in their personal lives" (Teacher 3). Students' participation in the design and layout, flow, of the project kept the interest undiminished throughout the project materialization, all over the school year. If students are involved in designing rubrics, they can contribute to feedback with their peers. When this is achieved, the classroom is transformed into a true community of learners (Farr \& Tone, 1998). According to FR stated that "There have been general discussions in order to approach each section so that students can see the dimensions of each step and actively participate in the design of the course of the study by making suggestions". In the initial meetings, the analysis of the issue and the choice of activities, applied with the brainstorming technique. "The students had heard in CD nature sounds, wrote many thoughts come to mind on cardboard was placed on the floor, in order to find the title and the themes of the project" (AF). Based on the approach of ecosystems management that students recorded in Macedonia and Crete, organized and made recommendations for the local ecosystems which addressed to the responsible bodies who had been invited to the Conference, in the end of Project materialization" (Teacher 1).

Learning from experience that focuses on real-world problems and utilizes multiple disciplines allows students to explore, discuss and build multidisciplinary scenarios and relations around issues that concern them. In this way, earning became authentic and activated complex skills, as critical thinking, information organization and creativity. "The designed various outdoor learning environments were positive for the learning procedure, arousing learner's positive emotions, such was fun and interesting for investigation in the field, with schoolmates, teachers, scientists, locals, fundamental cornerstone to building the socio-cultural context" (Teacher 2).

\subsection{Strengthening Communication and Relationships}

Citizens' participation in the protection and conservation of Nature, in order to ensure the viability of the area and the quality of life, are directly related to the students' active participation in social life and the creation of active citizenship. The partnership of governments, civil society, and business is essential for effective governance. In order to 
build a sustainable global community, the nations of the world must renew their commitment to the United Nations, fulfill their obligations under existing international agreements, and support the implementation of Earth Charter (2000) principles with an international legally binding instrument on environment and development (UN, 2015). Education needs to strengthen the social relationships, in preventing drop-out, through partnerships with the private and the public sectors. The social partners and communities focus on target groups and their needs to be successful (E-COM, 2006). "These proposals, once supported with arguments by those expressed, then passed and became the Project's objects" (Teacher 2). SPEEs can contribute to this direction if it is designed to exploit the power of social pressure, to help people to change behavior, although some argue that it is difficult to determine changes in environmental behavior since perceptions of what contributes to SD are changing constantly (Zygouri, 2005). "The Mayor of the Municipality invited to the school and interviewed all students of the Environmental Team, who addressed questions about the policy implemented and the interventions that intends to do in the forest of Epanosifi, in Astritsi gorge and the dam is being prepared" (FR). The ESDP can be combined with business activities of the students, which will generate revenue that can be used for beneficial purposes to fellowmen or for the school needs. Working together with people, in their regions and in the communities where they belong, raises the quality of life, strengthen and supports as part of group liability, feedback and communication (Rutherford \& Ahlgren, 1991). The schools that function as multi-purpose local learning centers ensure professional development to the teachers and trainers as well as to the quality of the offering education (Kalathaki, 2015). It is important to acknowledge the role of the society in enabling all members of the society to be actively engaged in local initiatives for SD. The improved participation of civil society depends upon inter alia, strengthening access to information, building civil society capacity as well as an enabling environment consciousness. Information and communication technology (ICT) is facilitating the flow of information between governments and the public by bridging the digital gap recognizing the contribution of international cooperation in this regard (Rio+20, 2012).

\subsection{Innovative Project Methodology \& Meaningful Educational Activites}

The methodological approach and the selection of teaching strategies depend heavily on the issue. Usually, selected methods are suitable for teamwork in small groups which aim to parallel transmission of knowledge and skills by cultivating friendly feelings and behaviors in the environment. The most popular method of designing and implementing a SPEE in Greek formal Education is the method of 'Research Essay', known also as 'Project Method' (Frey, 1998). This is also indicated in ESD. This method, combined with innovative educational techniques facilitated and made the project more interesting, with the application of didactic research, which stirred the interest of students and pushed them to get more involved in the educational process. "The processing of the subject will be interdisciplinary, multidisciplinary, with the assistance of teachers who teach literature, sociology, history, computers, theatre-ology in school" (AF).

Increasing participation of young people in representative democracy is one of the most important challenges facing European society. The Council of Europe, wanting to help this challenge, outlined ways to foster a culture of democracy in schools, involving students, 
parents and teachers with various participative, experiential ways of teaching and learning (EC, 2007). Organization of meetings, round tables, debates, ethical dilemmas, Socratic dialogues and discussions to exchange views, interviews, brainstorming, role play, environmental pathways, and guided tours should be greatly conducted together with the ICTs in various learning environments inside and outside the school, in the classroom, the libraries, the science laboratory, in the field and in society. These activities help learners to conquer a comprehensive picture of the negotiating environmental issue (Kokkotas et al, 2004; UNECE, 2005; NTUA, 2007). Simulations, experimentations, case studies, field works and excursions seek to engage learners in data analysis, facilitating the problem solving method. The educational games, as they offer more entertainment and joy, seek to find an environmental solution more comfortably.

The lecture is an educational technique which is widely used in formal and informal Education while its teaching value is disputed by many. In the project, it appears that its use was avoided as it is teacher-centered educational technique. Only "Gareth Owens developed a lecture on Linear A, the symbols of the Minoan civilization and the tree-worship of the ancient Greeks" (FR) and "the educational package of Goulandris Natural History Museum on the Greek Forests was presented with lecture" (Teacher 3).

The project actions focused on the synthesis of bio-communities and development of discussions on the ways of management and protection them to ensure future ecological sustainability and social quality of life. Students visited agro-touristic units in Macedonia and Crete, in different ecological environments. Many of the innovative educational techniques mentioned above were applied in project's activities. "These techniques, because they differ significantly from those previously students could experience in classrooms, increased the interest in participation" (Teacher 2). In the guided environmental interpretation, the role of the teacher as educator is advisory and equivalent to the role of the student-learners. The contact with society is ongoing, particularly with the individuals and groups involved in the environmental issue, the subject matter of the project, giving more importance to the procedure, rather than the final result, since education comes through the process, as Kavafis says in the poem 'Ithaca'.

The Environmental Team conducted observations in the forests on the composition of bio-communities and discussions about the biodiversity threats that students identified. Students realized many pollution sources in the aquatic and terrestrial ecosystems and intensively commented on the gaseous air pollution by the thermal power factory in Ptolemaida area and the compromising quality of life of the inhabitants because they strongly perceived this as they were crossing the region. "While investigating the issue, students posed the questions and then they worked in teams in order to find answers or solutions as more organized way they could" (Teacher 1). This student-centered teaching discovery method seems to promote the self-directed organization and structuring of content and learning procedure, making of correct choices and generally the maximization of learners experience. "We let free the students to think about what to do following and how they could accomplish what they wanted in each case" (Teacher 1).

In the tour sites, discussions developed with the guides on topics related to history, architecture and the habits of the locals. Teachers completing the work of the local guides made connections 
of the new knowledge with references of the subjects taught. They also prepared what they will teach in the courses of the upper classes. "Discussions developed with elders from the villages of Florina, on the streets or in the cafes on the use of forest land in the past, today and in the future. Thus began an intergenerational communication which intrigued students wanting more and more" (Teacher 1).

Regarding the laboratory teaching, "The Environmental Centre of Kastoria supported the experiential approach of our object on forest and lake ecosystems by sampling material from the lake's banks, observation with stereoscopes, systematic classification of the animal and plant samples with the use of scientific keys.

During the initial meetings of students and teachers, the brainstorm technique was utilized in choosing the topic, the objectives and content of the project. Assessment of the educational visit in Macedonia showed that the students were impressed by their experience of the brainstorming technique because on a banner they expressed what they experienced and impressed them.

The debates (speech in controversy groups) helps the cognitive conflict due to the multiple representations of ideas that occur in the process (Posner et al, 1982). The opposition groups have themselves to shoot down alternative ideas using the learning experiences that bring students face to face with signs, historical experiences and problems on the collection of data that is not consistent with their previous perceptions. The debates often resulted in ethical dilemmas, many times with scientific base where formulated questions, expressed opinions opposing views and suggested solutions (Athanasiou, 2008). The aspects of an environmental issue facing a community that must be explored in an ESDP, according to McKeown (2002), are the problem causes, the most important risks, the financial consequences, the implementation obstacles, the populations who will bear the cost of the solutions, the political dimension of the problem and its solutions, the relationship of the subject with other environmental issues, changes in everyday life of everyone that can reduce the problem, the next steps to be taken. This is similar to the pre-referred aspects developed by the students during their debate on the issue of development of rural areas at the agricultural lodging in Saint Achillion. "Students were divided into two groups and impersonated roles. Half were businessmen who wanted the region's development and the other half was locals who preferred to live as before. They strongly supported their views, without getting into a fight, however many were the arguments" (FR). Cognitive development as product of socio-cognitive conflict is positioned in the convergence point of the social and the cognitive approach (Doise \& Mugny, 1984; Komis, 1999). Socio-cognitive conflict is a process in which a person experiencing a problem makes some estimation received from the social environment a coherent response which defends with clarity. Thus, she/he realizes that, apart from her/his own point of view, there are other considerations which provide new information and different answers. Consequently, the socio-cognitive conflict serves as a mechanism through which the thought is driven to higher-level balancing.

In the AF is sited "role play-dramatization, will be represented situations in order to be highlighted conflicts and disputes and students will be exercised in the documented reasoning to find a compromise. With the above will result attitudes and behaviors". After departing from the Heraklion port to Piraeus, in the beginning of the educational visit to North Greece, set up 


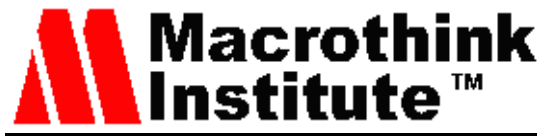

"a vestigial theatrical play, exercise might say, to get to know better the team personnel, teachers and students, thicken the team on board" (Teacher 2).

The interviews were excellent tool for gathering information, ideas and opinions from locals about their residence places. Several students interviewed elders from their villages on the use of forest Epanosifi, the threats and the measures that they think should be taken to be protected. In terms of issues of local development, except the discussion with the Mayor of local Municipality, students interviewed the forester of the Municipality. Also, "Students took interview from the Abbot of the monastery Epanosifi about the history of the monastery and the unique, homonym, forest area owned by the monastery" (FR). "Interviews took a team of students from two professionals engaged in rural tourism in a village of the school district and two from Prespes on issues related to buildings, the food, the conditions of work, the problems they have and how they overcome, the support they wish and receive from the State" (Teacher1).

\subsection{Dissemination of the Project Outputs and Outcomes}

According to the methodological methodology in EE, the synthesis of the actions to conclude the results of a SPEE premises the sampling and data processing, content analysis of archival material in tables, charts, histograms, collage, etc., the script writing with the activities, actions and experiences of the whole project, recommendations to avoiding negative consequences of human interventions, undertaking actions, further actions planning, etc., always with the eye on the dissemination of the project outputs and outcomes (NTUA, 2007). The presentation of the project results to the school community, the local council, parents and the local community became as an open conference at the end of the school year. "The students prepared the topics of the presentation using ICT, texts, photos and videos and, with a round table presented their experience to the public" (Teacher 3). "In many cases they gave explanations and discussion developed in response to questions put to them or putting themselves subjects for discussion. The presentation highlighted many areas of the Project relating to the design, construction and project implementation methodology, with particular emphasis on the experience gained during the educational visit in Macedonia" (Teacher 2). The key word is partnership and net-worked or collaborative ways of working can bring added value to operations as knowledge is shared and innovated in networks. Professionalism and expertise are no longer understood as personal properties, but closely tied to communities, organizations and networks (Wilson, 2006).

\section{Conclusions}

As the study revealed, the environment based-education is hypothesis not only for the school but also the government, environmental agencies, entrepreneurial initiatives, local authorities and other bodies because they play a major role in promoting students' understanding of environmental concepts and in promoting awareness of major environmental issues and positive attitude towards natural environment. The findings drawn from the archival material show that students' active participation in the educational process was linked both to the study of the ecosystem and the management by the local societies and also to the relations that were built up during the project implementation. However, this study is particularly focused on the descriptive, rather than on the explanatory level. So, the results are only indicative concerning the numbering of factors that push students to be more active in 
educational actions. It is interesting to notice that in spite of the fact that inquiry is out of the curriculum, the teachers made use of it to improve their teaching practices, and it seems to be the main reason of the highly active participation of students.

In preparing young Europeans for active citizenship, schools need to find out ways to foster a culture of democracy in schools by involving students, parents and teachers. Democracy requires a life-long learning process that has practiced at own level. Democracy in schools also has pragmatic justifications as it is an effective way for creating a climate of confidence and responsibility within schools which supports the sustainability of schools and local communities (EC, 2007).

\section{References}

Aegean. (2004). School Programs of Environmental Education. www.Aegean.gr/sppe, Aegean University, retrieved 20-12-2004.

Agrotouristiki, A. C. (2007). What is agro-tourism? Retrieved May 4, 2007, from http://www.agrotour.gr/agro/site/AgroTour/t_docpage?sub_nav=WhatIs\&doc=/Documents/ag rotour/company/whatisrural

Athanasiou, K. (2008). Discovery teaching method. Course Notes of Special Teaching in MSc "Current trends in the teaching of biological courses and new technologies" of the Department of Biology, University of Athens

Bell, J. (1997). Methodological Design of Pedagogical and Social Research, Publications Gutenberg, Athens

Callisto. (2008) Open Classes, Environmental Educational Program. Greek Ministry of Education and Religious. Retrieved from http://www.e-yliko.gr

Cohen, L., \& Manion, L. (1994) Educational Research Methodology, Metaichmio, Athens. Chrysafidis, K. (2006). Experiential-Communicative Teaching. The Introduction of the Project Approach to School Editions Gutenberg, Athens.

Cunningham, M. C., Meyer, Z. M., \& Avery, L. (2001). Promoting Sociologically Authentic Inquiry in School Science Communities, Paper presented at the Annual Meeting of the National Association for Research in Science Teaching, St. Louis, MO.

Dimitropoulos, E. (1996). Evaluation of Education and Training Programs, the evaluator Guide, Gregory Publications, Athens.

Doise, W., \& Mugny, G. (1984). The Social development of the intellect. New York, Pergamon.

Earth Charter. (2000). Earth Charter, http://www.earthcharter.org, Available 09-03-2008

E-COM. (2006). Efficiency and equity in European education and training systems, Communication from the Commission to the Council and to the European Parliament of 8 September 2006 on Efficiency and equity in European education and training systems $[\operatorname{COM}(2006) 481$ final - not published in the Official Journal], Available 12/05/2007 on http://eur-lex.europa.eu/legal-content/EN/TXT/?uri=URISERV:c11095

EC. (2006). Key competences for lifelong learning. Recommendation 2006/962/EC of the European Parliament and of the Council of 18 December 2006 on key competences for lifelong learning [Official Journal L 394 of 30.12.2006], available 050216 on 
http://eur-lex.europa.eu/legal-content/EN/TXT/?uri=URISERV:c11090

EC. (2007). Schools for the 21st Century, Commission Staff Working Document, Commission of the European Communities, Brussels, 11.07.2007, Sec(2007) 1009, available 23/09/2010 on http://ec.europa.eu/education/school21/consultdoc_el.pdf and 02/02/2016 on http://e-learning.sch.gr/pluginfile.php/7824/mod_resource/content/0/geniko_meros/enothta_1 /mathima_1/schools_for_the_20th_century.pdf

E-COM. (2007). A coherent framework of indicators and benchmarks for monitoring the Lisbon objectives Communication from the Commission of 21 February 2007 - "A coherent framework of indicators and benchmarks for monitoring progress towards the Lisbon objectives in education and training" $[\operatorname{COM}(2007) 61$ final]available 010216 on http://eur-lex.europa.eu/legal-content/EN/TXT/?uri=URISERV:c11099

Erasmus. (2016). Erasmus+ Programme Guide, Version 2 (2016), https://eacea.ec.europa.eu/documents/eforms_en

Farr, R., \& Tone, B. (1998). Portfolio and Performance Assessment: Helping Students Evaluate Their Progress as Readers and Writers. The United States of America: Harcourt Brace, College Publishers.

Frey, K. (1998). The Project Method, a form of collective work in school as theory and practice Translate Malliou K Publishing House Kyriakidis Brothers, Thessaloniki.

Hargreaves, A. (1990). Teachers' work and the politics of time and space. Qualitative Studies in Education 3, in Gomm Roger \& Peter Woods (translated in Greek by Petrogiannis Konstantinos) Educational Program 'Educational Research in action”, Greek Open University, Patra, 1999.

Hernandez, O., \& Monroe, M. C. (2000). Thinking about behaviour, in Environmental Education and Communication for a Sustainable World. Handbook for international Participants. USA: Academy for Educational Development

Huckle, J. (2006). Teaching and Learning in ESD: the case for critical pedagogy, University Notes Workshop 4-8 December, Graduate Program "Environmental Education" TEPAES, Aegean University, Rhodes

Iosifidis, T. (2003). Qualitative Data Analysis in the Social Sciences, Kritiki Publications, Athens.

Iosiphidis, T., \& Spyridakis, M. (2006). Qualitative Social Research, Methodological approaches and analysis. Kritiki Publications, Athens.

Kalathaki, M. (2015). The student environmental programs function as in-school teachers' self-training: an evaluation approach of the used methodology. International Journal of Current Research, 7(03), 14103-14111,

Kalathaki, M. (2016). Discovery teaching in a school project of education for the sustainable development: an evaluation case study. International Journal of Recent Scientific Research, $7(1), 8561-8567$.

Karountzou, G. (2007). Education for sustainable development. Environmental Education and Intercultural Education. Pedagogical approaches With Common Features, 3rd Congress of PEEKPE on Education for Sustainability and Environmental Education: 
Society-Economy-Environment-Culture, 9-11 November, Athens.

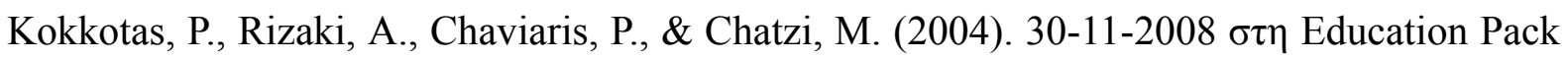
"Science for fifth grade", Teacher guide, available on the 30-11-2008 at http://www.primedu.uoa.gr/sciedu/biblio/bookTeachers/idroduce/4theories.htm

Komis, B. (1999). The influence of the social environment, available on 30-11-2008 at http://www.csd.uoc.gr/ hy402/lectures_transp/theories_mathishs_kai_ypologistes2/tsld023.ht $\mathrm{ml}$

Komis, B. (2004). Introduction to educational applications of Information Technologies and Communications, Athens Publishing New Technologies.

Lederman, N. G. (2004). Syntax of nature of science within inquiry and science instruction. In L. B. Flick, \& N. G. Lederman, (Eds.), Scientific inquiry and nature of science: Implications for teaching, learning, and teacher education (Chap. 14, pp. 301-317). Dordrecht, the Netherlands: Kluwer Academic Publishers. https://doi.org/10.1007/978-1-4020-5814-1_14

Matsagouras, H. (2007). Teaching Strategies (5th edition) Gutenberg, Athens.

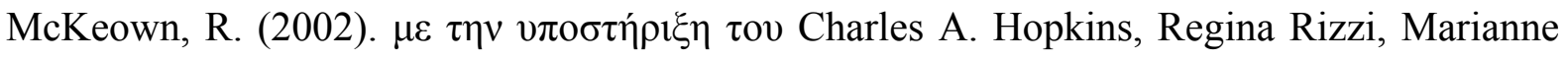
Chrystalbridge, Education for Sustainable Development-Toolkit Energy, Environment and Resources Center, University of Tennessee, USA.

NAAEE. (1996). Environmental education materials: Guidelines for excellence. North American Association for Environmental Education. Troy, OH: NAAEE.

NTUA. (2007). Educational material for Teachers and Executives Training Seminar of Environmental Education, EPEAEK II Writing Group with scientific responsible Professor Koutsopoulos K., National Technical University of Athens.

PI. (2007). Forest-Development-Environment Indicative Work Plan in the A / Secondary Education, Methodological Indicative Programme Planning Framework, available on 05/04/2007 at http://www.pi-schools.gr/drast/perivalontiki address /

Posner, G. J., Strike, K. A., Hewson, P. W., \& Gertzog, W. A. (1982). Accommodation of a scientific conception: Towards a theory of conceptual change. Science Education, 66(2)

Rio+20 (2012) “The_Future_We_Want", Conference_outcome_document, Rio+20 United Nations Conference on Sustainable Development, Rio de Janeiro, 20-22 June 2012, http://www.hellenicaid.gr/diethnes-plaisio/diethnes-plaisio/pagkosmia-diaskepse-gia-te-biosi me-anaptuxe-ton-ee-rio-20.html

Rutherford, J., \& Ahlgren, A. (1991). Science for all Americans, Oxford University Press, Project 2061, Benchmarks for Scientific Literacy, AAAS, Washington DC, available on 30-11-2008 at http://www.project2061.org/publications/sfaa/online/chap1.htm

UN. (2015). Transforming our world: the 2030 Agenda for Sustainable Development, Resolution adopted by the General Assembly on 25 September 2015, Seventieth session, Agenda items 15 and 116, A/RES/70/1, 21 October 2015

UNESCO. (2005). Guidelines and Recommendations for Reorienting Teacher Education to Address Sustainability, United Nations Decade of Education for Sustainable Development (2005-2014), Education for Sustainable Development in Action, Technical Paper $\mathrm{N}^{\circ} 2-2005$ 


\section{Macrothink}

Journal of Social Science Studies

ISSN 2329-9150

2017, Vol. 4, No. 2

UNESCO Education Sector

UNECE. (2005). UNECE strategy for ESD which adopted at the high-level meeting of Environment and Education Ministers in Vilnius 2005, http://www.unece.org/fileadmin/DAM/env/documents/2005/cep/ac.13/cep.ac.13.2005.3.rev.1. e.pdf

Vosniadou, S. (2001). How students learn, International Education Office of UNESCO, International Academy of Education.

Vygotsky, L. S. (1997). Mind in Society, Development of Higher Psychological Processes, translation Bibou A and Vosniadou S., Publisher Gutenberg, Athens.

Wang, H. H., \& Carlson, S. P. (2011). Factors that Influence Student's Satisfaction in an Environmental Field Day Experience. International Electronic Journal of Environmental Education, 1(2).

Wilson, J. R. (2006). Collaboration in Mobile virtual work: a Human factors view. In Mobile Virtual Work (pp. 129-151). Berlin: Springer. https://doi.org/10.1007/3-540-28365-X_6

Zahariou, A. (2007). Interdisciplinary in Environmental Education, Lecture Notes, Post Graduated Studies on Environmental Education, Aegean University, Rhodes, Greece, 2007.

Zygouri, E. (2005). Evaluation of environmental education programs: Theory and practice. Publications Tipothito, Athens.

\section{Copyright Disclaimer}

Copyright for this article is retained by the author(s), with first publication rights granted to the journal.

This is an open-access article distributed under the terms and conditions of the Creative Commons Attribution license (http://creativecommons.org/licenses/by/3.0/). 